\title{
Bodies and Space in the Timaeus
}

\author{
Ondřej Krása
}

\begin{abstract}
Bodies are shown to be related to something else from the very beginning of Timaeus' speech. The original twofold distinction between being and becoming is later on expanded by the addition of a third kind. In this paper, I try to shed some light on the relationship between bodies and the third kind. In the passage dealing with the three kinds $(48 \mathrm{a}-53 \mathrm{~b})$ relationship between bodies and the third kind has three prominent facets. First, bodies are "in" the third kind as in a receptacle or container. Second, bodies are modifications of the third kind and therefore parts of the third kind are bodies themselves. Third, bodies are modifications of the third kind that do not prevent other modifications from taking place. At the end of the section $48 a-53 b$, the third kind is identified with space, and starting from line 53 b bodies are shown to have a geometrical nature. From this perspective, we can see how the first two facets of the relationship of bodies to the third kind are materialized: a geometrical figure is both in space and it is a modification of space. However, Timaeus' third characterization of this relationship cannot be explained from this perspective. This inconsistency is due to the different connotations of bodies in both passages. In the passage dealing with the three kinds, bodies are shown to be an utterly dependent image of the eternal paradigm in the receptacle. In the passage dealing with geometrical nature of bodies, body is shown to be an independent and self-sufficient geometrical structure. Neither of these connotations should be rejected, and it is clear that Plato wants us to think about body as an image of eternal being, whose specific independence has a geometrical nature.
\end{abstract}

\section{Keywords}

Plato - Timaeus - body - space - geometry

Becoming is shown to be related to something else from the very beginning of Timaeus' speech. The original twofold distinction between being and becoming is subsequently expanded by the addition of a third kind. In this paper, I 
will try to shed some light on the relationship between corporeal becoming and the third kind. ${ }^{1}$

I will try to show that in the passage dealing with the three kinds $(48 \mathrm{a}-53 \mathrm{~b})$ this relationship has three prominent facets. ${ }^{2}$ First, becoming is "in" the third kind as in a receptacle or container. Second, becoming is a modification of the third kind and therefore parts of the third kind are becoming itself. Third, becoming is a modification of the third kind that does not prevent other modifications from taking place.

At the end of the section $48 \mathrm{a}-53 \mathrm{~b}$, the third kind is identified with space, and starting from line $53 \mathrm{~b}$ corporeal becoming is shown to have a geometrical nature. From this perspective, we can see how the first two facets of the relationship of becoming to the third kind are materialized: a geometrical figure is both in space and it is a modification of space.

However, Timaeus' third characterization of this relationship-becoming is a modification of the third kind that does not prevent any other modifications from taking place-cannot be explained from this perspective. This inconsistency is due to the different connotations of becoming in both passages. In the passage dealing with the three kinds, becoming is shown to be an utterly dependent image of the eternal paradigm in the receptacle. In the passage dealing with geometrical nature of bodies, becoming is shown to be an independent and self-sufficient geometrical structure. Neither of these connotations should be rejected, and it is clear that Plato wants us to think about corporeal becoming as an image of eternal being, whose specific independence has a geometrical nature.

1 Timaeus uses many words to describe the middle kind, e.g. to gignomenon (Tim. 27d6), genesis (Tim. 49a6), somma (Tim. 5ob6). Although the question of the relationship of the soul to the third kind is very important and has not been very much debated, I will deal with corporeal becoming only.

2 There is at least one more facet of this relationship, namely the moving/being moved relation of becoming to the third kind in the passage dealing with pre-cosmic becoming (Tim.

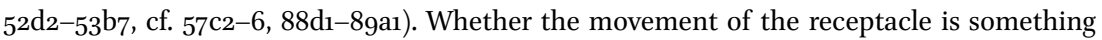
different from the movement of pre-cosmic becoming is dependent on the answer to the question whether there is a difference between pre-cosmic becoming and the receptacle. I am inclined to think that even pre-cosmic becoming is nothing other than a modification of the receptacle and therefore one cannot distinguish between the movement of receptacle and the movement of pre-cosmic becoming. For the identity of becoming and the receptacle, see the section 1.2 "Shapeless but Modified" below. 
In this section I will go through the relevant passages from the section $48 \mathrm{a}-51 \mathrm{~b}$ and I will identify three facets of the relationship of becoming to the third kind.

\subsection{A Difficulty with the Elemental Bodies}

In section $31 \mathrm{~b} 4-32 \mathrm{c} 4$, fire, earth, water and air were introduced as the primary constituents of the world which has come to be. In the section starting from $48 \mathrm{a}$, one of the first statements connected with the new beginning of the inquiry is that these elemental bodies are certainly not the principles and elements of everything. The reason for our previous misconception of the elemental bodies is said to be the fact that we have not shown their origin (genesis). ${ }^{3}$

Before Timaeus answers the question "What is then the origin of the elemental bodies?" he outlines the nature of the third kind. It is the receptacle (hypodochē) and nurse (tithēnē) of all becoming (pasa genesis). ${ }^{4}$ We will see how both characterizations are elaborated in the following sectionsbecoming is said to be in the third kind as in a container or receptacle, but there is also a more constitutive relationship between the third kind and becoming that is adumbrated by the designation "nurse."

\subsubsection{The Dependency of the Elemental Bodies}

At $49 b_{7}-c_{7}$, Timaeus says that the elemental bodies and similar physical entities seem to transmit their origin (genesis) to one another. ${ }^{5}$ We think that we see the thing we call water condensing and becoming (gignomenon) earth, or dissolving and becoming air, with the process continuing such that ignited air becomes fire, condensed fire turns back into air, and so on ... ${ }^{6}$

This passage puts the emphasis on the interdependency of each elemental body on the others-air is dissolved water, fire is ignited air, etc. But if we look more closely at what exactly it is that becomes one or the other elemental body, we can also identify the other principle which is going to play a key role in the following section of the dialogue. Timaeus starts his description by speaking about what we call water (ho hydōr ōnomakamen) which solidifies

3 Tim. $48 \mathrm{~b}_{5}-\mathrm{c} 2$.

4 Tim. 49a4-6.

5 Beside water, earth, air and fire, Timaeus mentions stones, wind, clouds and fog.

6 Earth has a distinctive position in this "circular becoming": earth is created out of water, but it gives rise to anything. Elements are not only created out of other elements, they also give rise to other elements. This distinctive position of earth adumbrates the role of the earth in the geometrical account of the bodies, see Tim. $54 \mathrm{~b}_{5} \mathrm{ff}$. 
and becomes earth, and becomes air, when the very same thing (tauton touto) dissolves and disperses. Although he refers in the majority of the cases to the elemental bodies themselves, which are transforming into other elemental bodies (e.g. synkautheis aêr), this mention of the "very same thing" being water, earth and air at different times is an adumbration of very important topic.

The origin of each elemental body is not simple, because air is not only air, but also the other element which has been changed into air. But, on the other hand, it is also the very same thing which was water and is now air. Elemental bodies are therefore not only interdependent on each other, which is the main emphasis of the current passage, but there is also an invariable principle going through all the changes of one elemental body into the other. An elemental body comes into being not only through the transformation of other elemental bodies, but also through the modification-e.g. condensation, dissolution, or ignition - of the very same thing which was modified differently prior to becoming the new elemental body. Each elemental body depends not only on another elemental body, e.g. air on water, it depends also on something permanent.

\subsubsection{This and Such}

The dependency of becoming on something permanent is further elaborated in the immediately following passage 49c7-5oa4, which further discusses the instability of becoming. These lines are notoriously difficult even to translate. There are two main ways of translating them, with many minor variants and corresponding interpretations. According to the traditional translation we should not call e.g. fire, which is an example of all that is becoming (gignomenon), ${ }^{7}$ by the name "this" (touto) but rather by the name "such" (to toiouton). According to the alternative translation we should not call that which is becoming by the name "fire," but we should call by the name "fire" only that which is on each occasion "such" (to toiouton hekastote). ${ }^{8}$

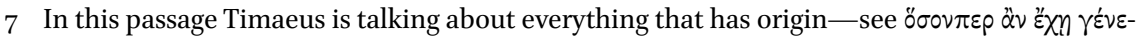
бıs (Tim. 49e7).

8 The alternative reading was established by Cherniss, "A Much Misread Passage of the Timaeus (Timaeus 49c7-50b5)." The traditional reading was defended against Cherniss by Gulley, "The Interpretation of Plato: Timaeus 49d-e." There have been numerous articles dealing with this problem since then. The proponents of the alternative reading after Cherniss are e.g. Lee, "On Plato's Timaeus 49d4-e7," and Silverman, "Timaean Particulars." The proponents of the traditional reading besides Gulley are e.g. Zeyl, "Plato and Talk of a World in Flux: Timaeus 49a6-5ob5," and Gill, "Matter and Flux in Plato's Timaeus 49d-e." 
The most difficult problem with the traditional reading is that Timaeus seems to say both that becoming is very unstable and fleeting ${ }^{9}$ and that it is "suchness" in all cases and that it is always moving around while being similar. ${ }^{10}$ Timaeus seems to attribute to becoming both instability and stability without stressing the transition or the meaning of this transition in any way.

The alternative reading is problematic primarily because of the new ontological realm it introduces. This new realm, which comprises the true object of reference of words like "fire," is characterized in terms of "self-identical characteristics."11 They are always the same, unlike the realm of becoming, but they move around unlike Forms. Although there is sometimes ambiguity about what is entering the receptacle, ${ }^{12}$ in his ontological divisions Timaeus never mentions this realm even though he divides ontological realms just a couple of lines above our passage, ${ }^{13}$ as well as a couple of lines below it. ${ }^{14}$

From a systematic point of view, the traditional reading is preferable. Unlike in the alternative reading, its main theses are in accord with the rest of Timaeus' speech and with the passage $48 \mathrm{a}-53 \mathrm{~b}$ particularly. ${ }^{15}$ Difficulties with the traditional reading can be mitigated by interpreting stability of the visible fire as a stable resemblance to Forms. Fire always resembles the Form of fire and as a "suchness" moves around while being similar. ${ }^{16}$

$9 \quad$ Tim. $49 \mathrm{e} 2-4$.

$10 \quad$ Tim. 49e4-7.

11 See e.g. Algra, Concepts of Space in Greek Thought, 102.

12 E.g. Tim. 5oc2-6.

13 Tim. 48e2-49a6.

14 Tim. 5oc7-d2. Similar argument against alternative reading are proposed by Gulley, "Timaeus 49d-e," 64, and Charles H. Kahn, "Flux and Forms in the Timaeus," 123-125. Cf. Phaed. $\operatorname{1o}_{5} \mathrm{~d} 5 \mathrm{ff}$. where Socrates speaks about forms (ideai, eidē) in sensible things, these forms are destructible. In the theory of geometrical atomism developed later in the Timaeus, there is one new ontological realm: triangles that never vanish. However, these triangles are not elements but are constituents of the elemental bodies and therefore they cannot be what the alternative reading calls self-identical characteristics. They are not e.g. "fire," but they are constitutive of fire, see Section 2 "Geometrical Figures and Space" below.

15 Besides being preferable from a systematic point of view, I think the traditional reading fits better into the immediate context of this passage. It answers the question raised at Tim. 49a7-b7 and 49c7-d4: What should we call e.g. the fire that appears to us? We should call fire "such" and never "this." It is also in accord with Timaeus' summary of his account in Tim. 5 b $2-6$.

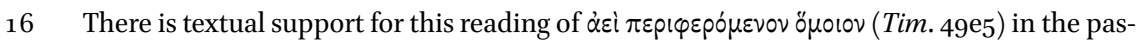
sage Tim. 52a4-7 where becoming is said to be always moving and similar to the Forms.

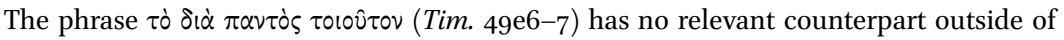
this passage. 
What can be deduced from the traditional translation of our passage? Becoming is not stable (monimon), but escapes (pheugei). Therefore we should not designate it by names indicating some measure of stability, but only by names that are more appropriate to its nature-i.e. we should not call it "this" but only "such." There is, however, another object of reference for the word "this." It is that in which becoming always becomes and appears, and from which it vanishes again. If we want to understand, for instance, what this visible fire in front of us is, we have to understand it as a "suchness" that is in something. Phenomenal fire has no nature of its own; it is nothing other than similarity to the Form of fire that appears in something else. Visible fire is to be understood from the perspective of two kinds of stability: the stability of the Form of fire and the stability of the receptacle in which it appears. Phenomenal fire depends on the one hand on a permanent "this," because fire always becomes in something, and, on the other hand, it is "suchness," because it resembles the Form of fire.

We have seen in the previous section $(49 \mathrm{~b} 7-\mathrm{c} 7$ the circular becoming of elements) that each phenomenal fire comes into being not only through the changing of other element into the form of fire, but also through the changing of something permanent that is modified into fire, but that was previously modified into air. In the passage about fire as "suchness" (49c7-5oa4), Timaeus speaks about permanent "thisness" in which something similar to the Form of fire appears. Both passages deal with the problem of naming something visible: How can one call something "fire," for instance, if this very thing was air before and will be air again? We should call it the "suchness" of some "thisness." Phenomenal fire that is changing into another element is constituted by the relation between the enduring Form of fire and the enduring receptacle. The enduring Form and the enduring receptacle provide us with the grounds for calling the thing in front of us "this fire."

This reading of $49 \mathrm{c}-5 \mathrm{Oa}$ is supported by the example of gold that is supposed to clarify this issue. ${ }^{17}$ If someone points at gold, which is ceaselessly reshaped from one form into another, and asks what it is, the most certain answer would be "gold." But we should also be happy, if we can call it, with some certainty, a "suchness," e.g. a "triangle." The triangular form is the form in the gold. Gold is the stable element, it is the "thisness." The triangular form is one of the always changing "suchnesses" of the gold, i.e. of the "thisness."

\subsection{Shapeless but Modified}

The relationship of becoming to the third kind is further elaborated in the passage ${ }^{\circ} \mathrm{ob}_{5}-51 \mathrm{~b} 6$. In this passage Timaeus describes the relationship between 
becoming and the third kind in both of the directions we have already identified - he underlines both that becoming is in the third kind as in the receptacle and therefore that it is in a way separate from it and that becoming is always the same thing which is modified in different ways. Let us look at these descriptions more closely.

In the first part of this passage ( $\left.5^{\circ} b_{5}^{-}{ }^{-} 5\right)$, Timaeus starts by saying that the third kind always receives all bodies, i.e. becoming, ${ }^{18}$ but that it never takes on the shape $(\text { morphēe })^{19}$ of any of the things which enter it and therefore it never departs from its character (dynamis). According to this description bodies are something different from the third kind which receives them and the characters of bodies and the third kind are also different - bodies have shapes which the third kind does not have and by entering into the third kind bodies do not change its character. The third kind is devoid of all the forms (ektos pantōn eidōn) of the things which enter it - the third kind receives bodies but it is never affected by them. This account is akin to the description of the receptacle which receives all becoming in itself- the third kind is in fact called "in which" also in this passage. ${ }^{20}$ This receptacle is different from the things which enter it, such that it does not take upon itself the shapes or forms of the things which are in it.

But, Timaeus continues, saying that the nature upon which all the impressions are made (ekmageion) is modified (diaschemmatizomenon) by the things that enter it and appears different at different times (phainetai allote alloion). According to this description, the third kind-quite surprisingly given the previous characterization - receives shape (schèma) from the things which enter it and it itself appears different. ${ }^{21}$ This description reminds us of a permanent thing which undergoes different modifications-becoming is some modification of the third kind.

18 "All bodies": ta panta sōmata Tim. 5ob6, "becoming": to gignomenon Tim. 5oc7-d.

19 Timaeus uses many different words to express what the third kind does not receive: morphē (Tim. 5oc1, see also Tim. 5od7: amorphon), idea (Tim. 5od7), ti tōn epeisiontōn (Tim. 5oe1-2), opsis (Tim. 5oe3), eidos (Tim. 5oe4). I do not think there is any substantial difference between these terms in our passage.

$20 \quad$ Tim. 5 od6.

21 Are bodies something different from the modified third kind which only appears different at different times or are they the same? For difference, see Silverman, "Timaean Particulars," 93. The receptacle is said to appear to be something in three passages (Tim. 5 oc2-4, $\left.5^{1 \mathrm{~b}} 4-6,5^{2} \mathrm{~d} 4-\mathrm{el}\right)$, but each time it is also modified. Since becoming is itself that which appears different at different times according to Timaeus' previous statements (Tim. 49c7-d1) we may be tempted to think that the third kind, which appears different, is identical with becoming. This alternative is confirmed when Timaeus says that the third kind likens itself (aphomoioi, Tim. 50e3), because in the very same passage becoming is itself called likeness (aphomoioumenon) of the Forms (Tim. 5od1, see also Tim. 51a2). 
What is, then, the relationship between these descriptions-becoming as something which does not affect the third kind in which it is and becoming as modification of the third kind?22 In the sentence beginning at 50c2, we are told that the second description is an explanation of the first one: the third kind does not take on any shape, since (gar) it is modified by receiving all impressions and therefore appears to be different at different times. The key to understanding this train of thought is to understand what it means to be the perfect receiver of all impressions (ekmageion panti). Timaeus explains this at 5od4-e4: that in which imprints (ektypōmata) are situated has to be completely shapeless in order to liken itself perfectly to whatever form it receives. If it had any form, it would exhibit not only the shape of the thing which is imprinted on it, but also its own appearance, and therefore it would not be a perfect receiver.

I interpret the apparent contradiction between these two characteristics of the relationship of becoming to the third kind in this way: the third kind is modified by the things which enter it, but it never really accepts the shapes of these things, because it is never modified in a way that would hinder other modifications from taking place. The third kind is modified, but the way it is modified never prevents it from being the perfect receiver: it is always capable of taking on any shape without qualification or resistance. This, I propose, is the meaning of Timaeus' statement that the third kind is modified but never accepts any shape.

Two similes exemplify the situation $\left(5^{\circ} 5^{-}-51 a 1\right) \cdot{ }^{23}$ First, the liquid which is the base for the scented ointments has to be made devoid of all possible

22 This double characterisation of the relationship between becoming and the third kind (sometimes referred to as the "receptacle paradox," Gregory, Plato's Philosophy of Science, 192-193, 211, 214-216) gave rise to the question whether the receptacle is "space" or "matter." Some interpreters think it is space only, e.g. Baeumker, Das Problem der Materie in der griechischen Philosophie: Eine historisch-kritische Untersuchung, 177-187, and Taylor, A Commentary on Plato's Timaeus, 312. Some think it is rather matter, e.g. Sachs, Die fünf platonischen Körper: Zur Geschichte der Mathematik und der Elementenlehre Platons und der Pythagoreer, 223-233. Still others think Timaeus uses both descriptions, e.g. Aristotle, Phys. 2ogbi1-17; Algra, Concepts of Space, 72-73, 76 ff.; Gregory, "Aristotle and Some of His Commentators on the Timaeus' Receptacle," 35; Miller, The Third Kind in Plato's Timaeus, 7, 17. For a more detailed classification of possible interpretations see Miller, The Third Kind, 19-32. The third kind has to be thought about from the perspective of its explicit identification with $\chi \omega \dot{\omega} \rho \alpha$ and from the geometrical nature of corporeal becoming, see section 2 "Geometrical Figures and Space."

23 Tim. 5ob5-51b6 contains one more simile; Timaeus likens the third kind to a mother, becoming to an offspring and being to a father (Tim. 5 od2-4, the third kind is called mother once again in Tim. 51a4-5; outside of our passage the Demiurge, and not being, is called father-e.g. Tim. 28c3, 41a7). We cannot infer much from this simile, because it is not 
scents at the start in order to be able to accept the intended fragrance perfectly. Second, the soft substance upon which impressions are made has to be devoid of all shapes at the start in order to accept whatever shape is intended. These two similes show that whatever is to properly imitate a characteristic, has to be without that characteristic. These similes work with two successive states - the before and the after. Before the liquid accepts fragrance it must be devoid of all fragrance and before the soft substance accepts shape it must be devoid of all shape. However, the third kind is different in this respect. The third kind is not only ready to accept any shape before it accepts a particular shape, but it is prepared to accept any shape even after it has already accepted a shape - it always accepts a shape, but it never hinders any other shape from appearing. ${ }^{24}$

Is it possible to be modified and not to hinder any other modification from taking place? Timaeus' examples are not of this kind. If the base for the scented ointments accepts a fragrance, it hinders other fragrances from being the only ones in the base: the first fragrance changes the odourless nature of the base. If a soft substance accepts, for instance, a triangular shape it will not accept, for instance, a square shape without any hindrance. It has to be remoulded with some effort.

Although Timaeus does not use the simile of the mirror in this context, it is probably the one which could best explain this strange relationship of becoming to the third kind. ${ }^{25}$ Mirror images are always in something, namely in a mirror, and are based on relationship between originals and observers mediated

worked out in any further detail. This simile is definitely part of the overall strategy of the passage-it is immediately followed by the explanation of what it is to be the perfect receiver and the second occurrence of the designation "mother" is accompanied by the receptacle. I think Cornford is right in pointing out that the notion of mother, father, and offspring Timaeus has in mind is that of mother as a mere host of the child whose father is the only cause of its generation, Cornford, Plato's Cosmology, 187. This simile thus underlines the notion of becoming as being just "in" the third kind without affecting it in any way. It is thus one part of the twofold characterization of the third kind spoken of above.

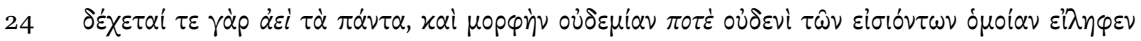

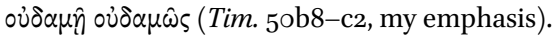

25 Timaeus mentions mirrors in different contexts in Tim. 46a2-c6 and 71a7-e2. Lee uses the mirror simile as a key to understanding Timaeus' metaphysics of becoming, see Lee, "On the Metaphysics of the Image in Plato's Timaeus," especially $35^{2-36}$. There are many differences between a mirror and the receptacle: the model, the mirror and the image are things of the same kind (spatio-temporal things), whereas the Forms, the receptacle and becoming are not on the same ontological level; most mirrors do not represent originals without distortions (e.g. inversions of the image on the horizontal axis), while the receptacle is the best thing, in which copies can arise; in order for there to be an image in a mirror, there has to be someone who observes it, while in the pre-cosmic becoming, on the 
by the parts of the mirror. The part of the mirror which now reflects the tree for me offers no resistance whatsoever to reflecting any other original to any other observer. The mirror always remains ready to reflect whatever shape it receives - in this way the mirror is itself without any shape although it already reflects a particular shape.

Is this the way Timaeus considers the relationship of becoming to the third kind? I will deal with this question later, after I have examined the nature of corporeal entities.

At the end of the passage $5 \mathrm{ob}_{5}-51 \mathrm{~b} 6$ (51a1-b6), Timaeus confirms the double nature of this relationship: In its nature (physis) the third kind is a receptacle (hypodochē) which is shapeless (amorphon) and it is improper to call it by the name of any shape, but it accepts shapes in its parts and as a whole, and is modified (e.g. pepyrōmenon, hygranthen) and therefore its parts are most correctly called by whatever shape they accept. ${ }^{26}$

\section{Geometrical Figures and Space}

In the analysis of various passages from Timaeus $48 \mathrm{a}$ to $5 \mathrm{lb}$, I tried to show that there are three interconnected facets of the relationship between becoming and the third kind: first, becoming is in the third kind as in a container; second, becoming is a modification of the third kind; third, becoming is a modification of the third kind that does not change the character of the third kind so that it never prevents other modifications from taking place.

In this section, I will try to show that looking at this threefold relationship from the perspective of the identification of the third kind with space and from the perspective of the geometrical nature of corporeal entities can explain some but not all of the obscurities in this relationship.

After Timaeus provides proof of the existence of the kind of being in itself, ${ }^{27}$ he continues to discuss the three kinds in the passages $51 \mathrm{e} 6-52 \mathrm{~d} 1$ and

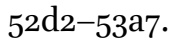

other hand, there is no one to perceive it. For a discussion of further differences between receptacle and mirror see Kung, "Why the Receptacle is not a Mirror," 167-178. part" (to pepyrōmenon meros) and "accepts imitations" of, for example, fire (mimēmata dechomai, Tim. 51b4-6). The verb "accept" (dechomai) is very common in describing what the third kind does with regard to becoming. 
In the first passage Timaeus characterizes becoming as that which becomes in some place and vanishes out of it again. ${ }^{28}$ We have already met a rather similar characteristic in the previous passages, where Timaeus told us that there is something in which all things come to be and appear and out of which they again vanish. ${ }^{29}$ Now Timaeus establishes what it is in which all becoming becomes: all becoming becomes in some place (en tini topōi). Thus the third kind is space (chōra) providing a location (hedra) for all becoming. ${ }^{30}$ Becoming has to be somewhere, i.e. it has to be in some place and occupy some space (chōra). ${ }^{31}$ The third kind provides the place, or space, or situation or whatever name we will use, for becoming, which is in it, because the third kind is space itself. ${ }^{32}$

Section $5^{2 \mathrm{~d} 2-53 a 7}$ deals with the situation before the heaven came into being. In this final passage of the dialogue, which is dealing explicitly with the three kinds, the third kind is confirmed to be space and the relationship of becoming to the third kind is described predominantly in a way that suggests that becoming is a modification of the third kind: the third kind was made watery and ignited and received the shapes (morphas) of earth and air before the heavens came into being.

Is identification of the third kind with space of any help with regard to the threefold relationship of becoming to the third kind? In order to answer this question, we must move forward to the passage where Timaeus shows what the nature of corporeal entities is. ${ }^{33}$

Fire, earth, water, and air are bodies. Each body which has plane faces is composed of triangles of two sorts, the first being right-angled isosceles triangles, the second being right-angled triangles with a hypotenuse double the length of the shorter side (by being doubled this triangle forms an equilateral triangle). ${ }^{34}$ From these two types of triangles two larger plane figures are formed: the equilateral triangle is formed by putting together six right-angled scalene triangle and the square is formed by putting together four right-angled

$28 \quad$ Tim. 5 2a6-7.

29 Tim. 49e7-5oa1, see also 5od6.

3о Tim. 52a8-b1.

$31 \quad$ Tim. $5^{2 b} 3-5$.

32 In many contexts in the Timaeus, chöra, topos, and hedra are used interchangeably, see Johansen, Plato's Natural Philosophy, 127-128. For the not very clear distinctions among these terms in antiquity, see Algra, Concepts of Space, $31-38$.

33 Some interpreters think that one should not connect these passages, Cornford, Plato's Cosmology, 182-183, Gregory, "Commentators on the Timaeus' Receptacle," 35, Gregory, Plato's Philosophy of Science, 212 and 221-222.

34 Aristotle criticizes Plato for not carrying out his analysis of solids further than into plane faces. See Aristotle, De gen. et corr. $315 \mathrm{~b} 3 \mathrm{o}-32$. 
isosceles triangles. Out of these plane figures four regular solids are formed: four equilateral triangles form a four-sided pyramid, eight of these form an octahedron and twenty of these form an icosahedron; meanwhile, six squares form a cube. Each of these regular solids is assigned to a particular elemental body: the four-sided pyramid to fire, the octahedron to air, the icosahedron to water, and the cube to earth. ${ }^{35}$ This account of the structure of the elemental bodies is referred to as geometrical atomism. ${ }^{36}$

Timaeus does not speak explicitly about the three kinds in the passage dealing with geometrical figures and it has been the subject of much criticism that Plato does not use the concept of the third kind in this passage. ${ }^{37}$ Although Timaeus does not mention the terms "third kind," "nurse," or "receptacle," he uses the terms "space," "place" and "seat" many times. ${ }^{38}$ The predominant usage of "space," "place" or "seat" (chōra, topos, hedra) identifies "where" some

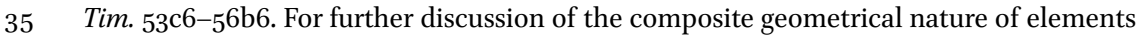
see Cornford, Plato's Cosmology, 230-239.

36 See e.g. Gregory, Plato's Philosophy of Science, 187-240. Labelling this account "geometrical atomism" should not lead us astray - in this passage Timaeus' universe is not as reductive as the label might suggest. Even though the various processes of coming to be of elemental bodies ( Tim. $5^{6 c 7-57} \mathrm{~b}_{7}$ ), their various types of characteristics (Tim. $5^{8 \mathrm{c} 5}$ $61 \mathrm{c2})$ and the various sensations we have of them (Tim. 61c3-68d7) are explained by way of the dissolution of regular solids into more basic plane figures and their regrouping into another regular solid and by way of the shapes, sizes, and groupings of these solids, there is lot more in universe than just shapes, sizes, and groupings of geometrical figures. For instance, there are characteristics of geometrical bodies, which are closely related to their shapes, like mobility and pliability, stability, sharpness, and lightness (Tim. 55e1-56c7). Timaeus' description of change is where principles that are not convertible into shapes, sizes, and groupings of geometrical figures start to play an eminent role. Change occurs only when there is diversity -in the realm of geometrical figures, there is no change among the same figures. The direction of the change is determined by the strength of the diverse parts involved in it. The stronger part makes the weaker assimilate into its own form—strength and weakness being related to, but not identical with, the amount of respective parts (Tim. $5^{6 \mathrm{e} 2}-57 \mathrm{~b} 7$ ). Besides the diversity of parts, locomotion is caused by the movement of the receptacle (Tim. $57 \mathrm{~b} 7-\mathrm{c} 6$ ). The reason why the movement of different elements never stops is the compression caused by the circular movement of the universe for which the world soul is responsible $(58 \mathrm{a} 2-\mathrm{c} 4)$. In order to make Timaeus' account credible, answering the question why the triangles compose in exactly this way, is also needed, see Aristotle, De caelo 299b23-31.

37 See Aristotle, De gen. et corr. 329a13-24; Lee, "The Image in Plato's Timaeus," 349-352; Gadamer, "Idee und Wirklichkeit in Platons Timaeus," 259.

38 The only two usages of the names of the third kind after the passage Tim. $48 \mathrm{a}-53 \mathrm{~b}$ is dechomenès at Tim. $57 \mathrm{c} 3$ and trophon kai tihènèn tou pantos at Tim. 88d6-but in these lines there is no specific connection with the geometrical nature of corporeal entities. 
corporeal entity is. There is e.g. a seat of fire ${ }^{39}$ and a place of fire..$^{40}$ The second usage which is also widespread is "to where/from where" some corporeal entity is moving. Everything is e.g. changing places (chōra) ${ }^{41}$ everything is moving to its own place (topos) ${ }^{42}$ The third usage is linked to the general structure of the universe. There is no empty space, ${ }^{43}$ no two opposite places "up" and "down" in the universe, ${ }^{44}$ but only relative places of "up" and "down" only ${ }^{45}$ There is also the central place of the universe ${ }^{46}$ and there are places for the masses of each elemental body. ${ }^{47}$

The first and the second type of usage of space/place/seat is akin to the "that in which" relation of becoming to the third kind. Becoming is in the third kind as in a receptacle or a container-geometrical figures are in space: they are in a place and they are moving from one place to another one.

Although the second type of relationship between becoming and the third kind, namely becoming as a modification of the third kind, is never mentioned in this passage, I think we can deduce it based on the geometrical nature of becoming. Corporeal entities have a geometrical nature. Geometrical figures consist of plane figures arranged so as to form the boundaries of solid figures"figure is the limit of a solid."48

In the Timaeus, there is nothing filling in the boundaries of the figure other than space itself. Not only is no mention of any specific filling made in the Timaeus, but, more importantly, no filling can logically be present. Timaeus' account of the change of one elemental body into another one works only if we take into account the limits of the solid figures and not the specific filling of solid figures: e.g. by dividing one unit of water, one unit of fire, and two units of air can arise. ${ }^{49}$ This is possible because the number of boundary triangles of one unit of water (icosahedron) equals the number of boundary triangles of one unit of fire (pyramid) plus two units of air (octahedron). But the volume of one icosahedron does not equal the volume of one pyramid plus

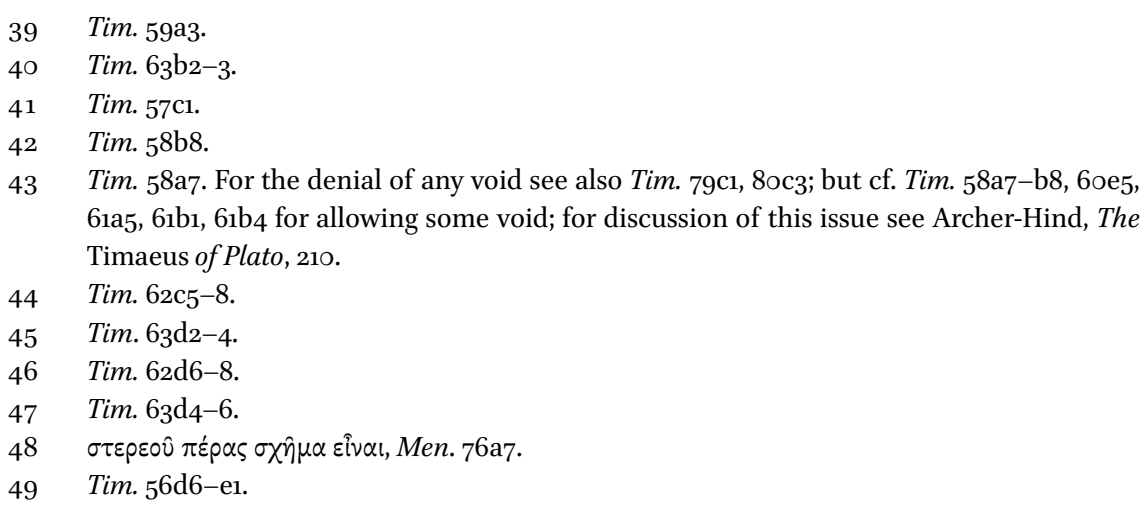


two octahedrons and therefore Timaeus' account of transformations of the elements works only with the triangular boundaries of solid figures and not with respect to its filling. What makes water water is not a specific filling in the icosahedron but only the arrangement of its boundary triangles in a specific way. What is relevant to the solid figure is its shape alone. ${ }^{50}$

If this is the nature of corporeal entities, we can consider corporeal entities to be a modification of space. Geometrical figures are limitations of space, they are parts of space shaped in a certain way by boundary triangles-there is nothing more in geometrical figures than space shaped in a certain way. ${ }^{51}$

Timaeus says that becoming is in the third kind, it is modification of it, but becoming never affects the third kind. We have seen that the motivation behind this last characteristic is that the third kind has to be always ready to accept any modification.

I have tried to show that some kinds of images meet this descriptionimages reflected in the mirror do not hinder other images from modifying the mirror in different ways. ${ }^{52}$ Why is this so? Images in the mirror do not hinder other images from appearing because the relationships among these images are only apparent. There is no direct relationship between one mirror image and another mirror image, every relationship is in fact a relationship between the originals and the observers. Because there are no direct relationships between reflections in the mirror, these reflections cannot hinder other reflections from taking place.

However, geometrical figures are not only dependent on the originals, they also have relationships with each other. Geometrical figures, for instance, move to the place where similar figures are, cut other figures into their constituent

50 For similar arguments see Baeumker, Das Problem der Materie, 172-175 and Vlastos, Plato's Universe, 89-9o. Why are geometrical figures solid if no filling is present? The basic triangles and the four geometrical figures have shapes which are beautiful and best (Tim. 53 b1-7, 54a1-b2). These characteristics are probably the reason why geometrical figures are solid for a certain period of time: in order for there to be a constantly moving mixture of elements, geometrical figures must preserve their shape for a certain time and then change into another element (Tim. 58a2-c4). The stability of the basic triangles is necessary for the creation of the elements from the destruction of other elements. The impenetrability of geometrical figures is due to their beautiful shapes which enable them to be part of the best and most beautiful world. A similar interpretation, together with serious objections, is provided by Gregory, Plato's Philosophy of Science, 237-238.

51 For similar interpretation see Zeller, Die Philosophie der Griechen in ihrer geschichtlichen Entwicklung:Teil II, Abt. 1 : Sokrates und die Sokratiker, Plato und die alte Akademie, 736. For systematic problems with this interpretation, see Gregory, Plato's Philosophy of Science,

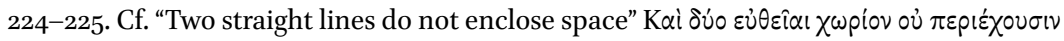
(Euclid, Elements, KE, 9).

See the section 1.2 "Shapeless but Modified" above. 
plane faces, and push each other out of the way. These relationships are not only apparent. Although these relationships are based on the relationships between the originals (otherwise there would not be any difference between fire and air, for example), the relationships between geometrical figures themselves do not mirror the relationships among originals. The reason why, for example, fire cuts water into its constituent pieces is not the relationship between Form of fire and Form of water. The reason why this process occurs is that a specific pyramid encounters specific icosahedron in space and the former is stronger than the latter.

Although identification of the third kind with space and geometrical nature of corporeal becoming sheds some light on the complex relationship between becoming and the third kind, there is still substantial difference between this relationship and relationship between geometrical figures and space. Geometrical figures are both in space and are a modification of space. Because the third kind is explicitly identified with space and corporeal becoming has a geometrical nature, we can see how becoming is both in space and how it is modification of space. However, geometrical figures are not the kind of modification that does not hinder other modification from taking place.

Timaeus does not seem to be bothered with this discrepancy. Why does he not explain physical becoming more radically as a mere reflection of the originals and instead attributes a certain self-sufficiency to relationships among corporeal entities?

Timaeus tries to do justice to our experience with corporeal entities: fire burns ${ }^{53}$ and earth is hard. ${ }^{54}$ Solids are impenetrable and therefore can directly affect each other. But why did the Demiurge create the world in this way? Why was the world created with specific relationships among corporeal entities that do not reflect the relationships between originals only? The Demiurge created the world as self-sufficient (autarkēs) ${ }^{55}$ and self-sufficiency is one of the ways in which the world resembles its model, which is "by itself." 56 The self-sufficiency of the world takes many forms. ${ }^{57}$ The self-sufficiency

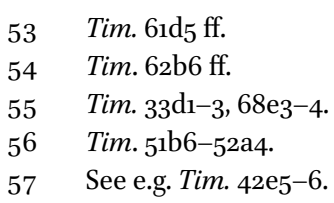


of the corporeal entity consists in preserving its shape and thus in identity with itself. This self-sufficiency resembles the self-sufficiency of the model, because that which is "by itself" neither receives anything else into itself nor enters into anything else. ${ }^{58}$ Corporeal entities do not enter into each other for some time, they are impenetrable. Impenetrability is a way in which corporeal becoming resembles being in itself.

Why does Timaeus describe the third kind as that which is shapeless first and becoming as stable geometrical form of the space later on? Are we right in interpreting becoming as a modification of the third kind that does not prevent other modifications, given that Timaeus thinks about a physical entity as something that prevents other things from entering the same place?

These tensions in Timaeus' account stem from the different perspectives found in our passages. In the passage dealing with elements in terms of images of the eternal beings that are in the receptacle, dependency on becoming is underlined: corporeal becoming has neither its form nor that in which it becomes from itself. Physical entities are not "this," but only "such," that is, they are unstable resemblances of eternal being. On the other hand, geometrical atomism portrays corporeal becoming as stable and independent: neither unchanging basic triangles nor temporarily stable geometrical figures are depicted as images of eternal being and their stability is not presented as an imitation of an eternal model. In the first passage, Timaeus underlines the absolute dependency of becoming on its model and on the receptacle. In the second passage, he underlines stability and self-sufficiency of becoming. These two emphases should not make us abandon one or the other perspective. We should rather take into account both of them and think about corporeal becoming in terms of images of eternal beings in the receptacle that are in a way stable and independent due to their geometrical nature.

In the Timaeus, there is no such account of corporeal becoming that bridges this gap. I tried to show above which aspects of the relationship of becoming to the third kind are preserved in the geometrical account of corporeal world. Timaeus identifies the third kind with space and space is essential in the geometrical atomism in two respects which are shared with the role of the third kind towards corporeal becoming. Space is both that in which geometrical figures are and that which is shaped in the form of geometrical figures: geometrical figures are in space and they are modifications of space. The third type of relationship between becoming and the third kind is not preserved in the relationship of geometrical figures to space: geometrical figures are solid and therefore they are not the kind of modification of space that does not hinder 
other geometrical figures from occupying the same place. The reason for this impenetrability of bodies is not geometrical, because in geometry figures can penetrate each other. The solidity of the figures is not due to the incapacity of space to be a perfect receiver. Rather, it is due to the aim of the Demiurge to create a world that is in some respects independent. The Demiurge creates elements as arrangements of space that are regular and beautiful and therefore that are able to temporarily preserve their shapes in spite of the opposing influence of other elements. ${ }^{59}$

\section{Works Cited}

Algra, Keimpe. Concepts of Space in Greek Thought. Leiden: Brill, 1995.

Archer-Hind, R. D. The Timaeus of Plato. London: Macmillan and Co., 1888.

Baeumker, Clemens. Das Problem der Materie in der griechischen Philosophie: Eine historisch-kritische Untersuchung. Münster: Aschendorffsche Verlagsbuchhandlung, 189 o.

Cherniss, Harold. "A Much Misread Passage of the Timaeus (Timaeus 49c7-5ob5)." The American Journal of Philology 75 (1954): 113-130.

Cornford, Francis M. Plato's Cosmology: The Timaeus of Plato. Indianapolis: Hackett Publishing Company, 1935. Reprint 1997.

Gadamer, Hans G. "Idee und Wirklichkeit in Platons Timaios." In Gesammelte Werke, Band 6: Griechische Philosophie II. Tübingen: Mohr Siebeck, 1985.

Gill, Mary L. "Matter and Flux in Plato's Timaeus 49d-e." Phronesis 32 (1987): 34-53.

Gregory, Andrew. Plato's Philosophy of Science. London: Duckworth, 2000.

Gregory, Andrew. "Aristotle and Some of His Commentators on the Timaeus' Receptacle." In Ancient Approaches to Plato's Timaeus. Edited by Robert W. Sharples and Anne Sheppard. London: Institute of Classical Studies, 2003.

Gulley, Norman. "The Interpretation of Plato: Timaeus 49d-e." A Journal of Philosophy 81 (1960): 53-64.

Johansen, Thomas K. Plato's Natural Philosophy: A Study of the Timaeus-Critias. Cambridge: Cambridge University Press, 2004.

59 I am grateful for many comments, especially those from Štěpán Špinka and Andrew Gregory. This paper was supported within the project of Operational Programme Research, Development and Education (OP vVv/OP RDE), "Centre for Ethics as Study in Human Value," registration No. CZ.02.1.01/o.o/0.o/15_003/oooo425, co-financed by the European Regional Development Fund and the state budget of the Czech Republic, and by Charles University in Prague, Faculty of Arts, program "svv 2014," project "The Cause of the World in Timaeus." 
Kahn, Charles H. "Flux and Forms in the Timaeus." In Le Style de la pensée: Recueil de textes en hommage à Jacques Brunschwig. Edited by Monique Canto-Sperber and Pierre Pellegrin. Paris: Les Belles Lettres, 2002, 113-131.

Kung, Joan. "Why the Receptacle is not a Mirror." Archiv für die Geschichte der Philosophie 70 (1988): 167-178.

Lee, Edward N. "On the Metaphysics of the Image in Plato's Timaeus." Monist 50 (1966): 341-368.

Lee, Edward N. “On Plato's Timaeus 49d4-e7." American Journal of Philology 88 (1967): $1-28$.

Miller, Dana. The Third Kind in Plato's Timaeus. Göttingen: Vandenhoeck \& Ruprecht, 2003.

Sachs, Eva. Die fünf platonischen Körper: Zur Geschichte der Mathematik und der Elementenlehre Platons und der Pythagoreer. Berlin: Weidmann, 1917.

Silverman, Allan. “Timaean Particulars.” Classical Quarterly 42 (1992): 87-113.

Taylor, Alfred E. A Commentary on Plato's Timaeus. Oxford: Clarendon Press, 1928.

Vlastos, Gregory. Plato's Universe. With a new introduction by Luc Brisson. Las Vegas: Parmenides Publishing, 2005.

Zeller, Eduard. Die Philosophie der Griechen in ihrer geschichtlichen Entwicklung: Teil II, Abt. 1: Sokrates und die Sokratiker, Plato und die alte Akademie. Third Edition. Leipzig: Pues's Verlag, 1875 .

Zeyl, Donald J. "Plato and Talk of a World in Flux: Timaeus 49a6-5ob5." Harvard Studies in Classical Philology 79 (1975): 125-148. 